\title{
Chemistry Underneath the Painting Surface: Palmierite Formation in/on a Painting by Johannes Vermeer and by Jacob Jordaens using Laboratory- and Synchrotron- aided Spectroscopic Methods
}

\author{
Jaap J. Boon
}

\section{JAAP Enterprise for Art Scientific Studies, Nieuwendammerdijk 79, 1025 LD Amsterdam, NL}

In the course of studies on The Art of Painting by Johannes Vermeer (1632-1675) and The Ferry Boat by Jacob Jordaens (1593-1678), large and numerous aggregates of a whitish substance were observed with EDX elemental characteristics of potassium, lead, sulfur and oxygen, and the FTIR markers for sulfate. In the case of the Vermeer painting it is accompanied by red colored fine-grained substances around the whitish aggregates. The analytical strategy to identify this material involved the sampling of microsample of the paintings, embedding and polishing to obtain cross sections of the paints with the suspected unknown material, the examination with imaging FTIR and FE-SEM-EDX at AMOLF (NL), imaging Xray-micro-tomography of cross sections (TOMCAT) and imaging microXRD/XRF of a thin section (Micro-XAS) at the PSI synchrotron in Villigen $(\mathrm{CH})$.

The red colored aggregated material in the Vermeer's Art of Painting [1] made in 1666/7 (KHM Vienna) was found in the craquelure, in pin-point losses and at the contact of the canvas and the ground layer where it had intruded and precipitated along cracks or grown inside the paint. Similar whitish aggregated material was also discovered in and on the lead white surface paint layer. FE-SEM-EDX and imaging FTIR of a paint cross section led to the discovery of a potassium sulfate aggregate (width $18 \mu$ ) surrounded by potassium lead sulfate (width $45 \mu$ ) as an intrusion in the ground paint, which strongly points to soluble potassium sulfates that penetrated the painting [Fig. 1]. The German lining of the painting with animal glue (gelatin) and alum in the $19^{\text {th }}$ century is suspected to be the source of the potassium sulfate as the aluminum precipitates with the protein at the reverse. A lengthy (3 years) restoration of paint delamination at the paint surface in 1998 involved repeated exposure to watercontaining glueing solutions, which could have soaked the canvas, thus mobilizing the potassium sulfate. Those same solutions are thought to have solubilized iron from the iron containing earth pigments in the ground. Potassium sulfate reacts with lead soaps to lead potassium sulfate (palmierite) forming large crystalline masses while mobile iron sulfates react to red colored iron oxides (haematite).

The Ferry Boat by Jordaens [2] made in 1623 (SMK Copenhagen) received many restorative interventions during its lifetime due to its large size and frequent moving between display locations over the centuries. Jordaens used an existing painting of which some parts are over-painted and added several pieces of canvas. A sample of the sky from Canvas IV was taken for analysis since its surface was covered with thousands of about $80 \mu$ diameter lumpy aggregates. FE-SEM-EDX and FTIR imaging data point to potassium-lead-sulfates. An Argon ion-polished cross section shows a large nanocystalline aggregate $(80 \mu$ wide $\times 35 \mu$ thick) on the paint surface. The EDX maps in Fig $2 \mathrm{~A}, \mathrm{~B}, \mathrm{C}$ demonstrate the elemental compositions of the glass $(\mathrm{Si})$, lead white/lead soaps $(\mathrm{Pb})$ and potassium $(\mathrm{K})$. A thin section of this cross-section surface was prepared for imaging micro-XRD and XRF using the MicroXAS beam line at the PSI synchrotron in Villigen (Switzerland). Imaging data were taken in transmission with a pixel size of 1x1 micron using a 2D-array camera. The XRD identifies the aggregate nanocrystals as palmierite. The palmierite XRD image map of the aggregate matches the 2D FSEM, EDX maps and FTIR data. The potassium is derived from the smalt (Co-soft glass) used as pigment in a lead white oil 
paint matrix. The source of the sulfate does not appear to be from the paint materials unless the original cobalt ore contained sulfate as well as the observed arsenates. Sulfur dioxide from coal burning stoves is a possible external source.

\section{References:}

[1]. Jaap J. Boon and Elke Oberthaler, In:Vermeer, Die Malkunst - Spurensicherung an einem Meisterwerk : Ausstellungskatalog des Kunsthistorischen Museums Wien 2010 / ed. Sabine Haag, Elke Oberthaler and Sabine Pénot. - Wien: Residenz Verl., 2010. - pp. 235-253. English text: pp. 328-335 \{http://nl.wikipedia.org/wiki/Bestand:Jan Vermeer - The Art of Painting - Google Art Project.jpg\}

[2]. Jordaens. The Making of a Masterpiece. 120 pages. ISBN 978-97-92023-

26-1_\{http://foto.smk.dk/index.php?p=KMS3198.jpg\}

[3] Acknowledgements: Elke Oberthaler (KHM Vienna), and J.Wadum, T. Filtenborg and J. H. Verhave (SMK Copenhagen) for making paint samples available and discussion of results. D. Grolimund and C. Borca from PSI for access to the MicroXAS beam line and assistance with data acquisition.

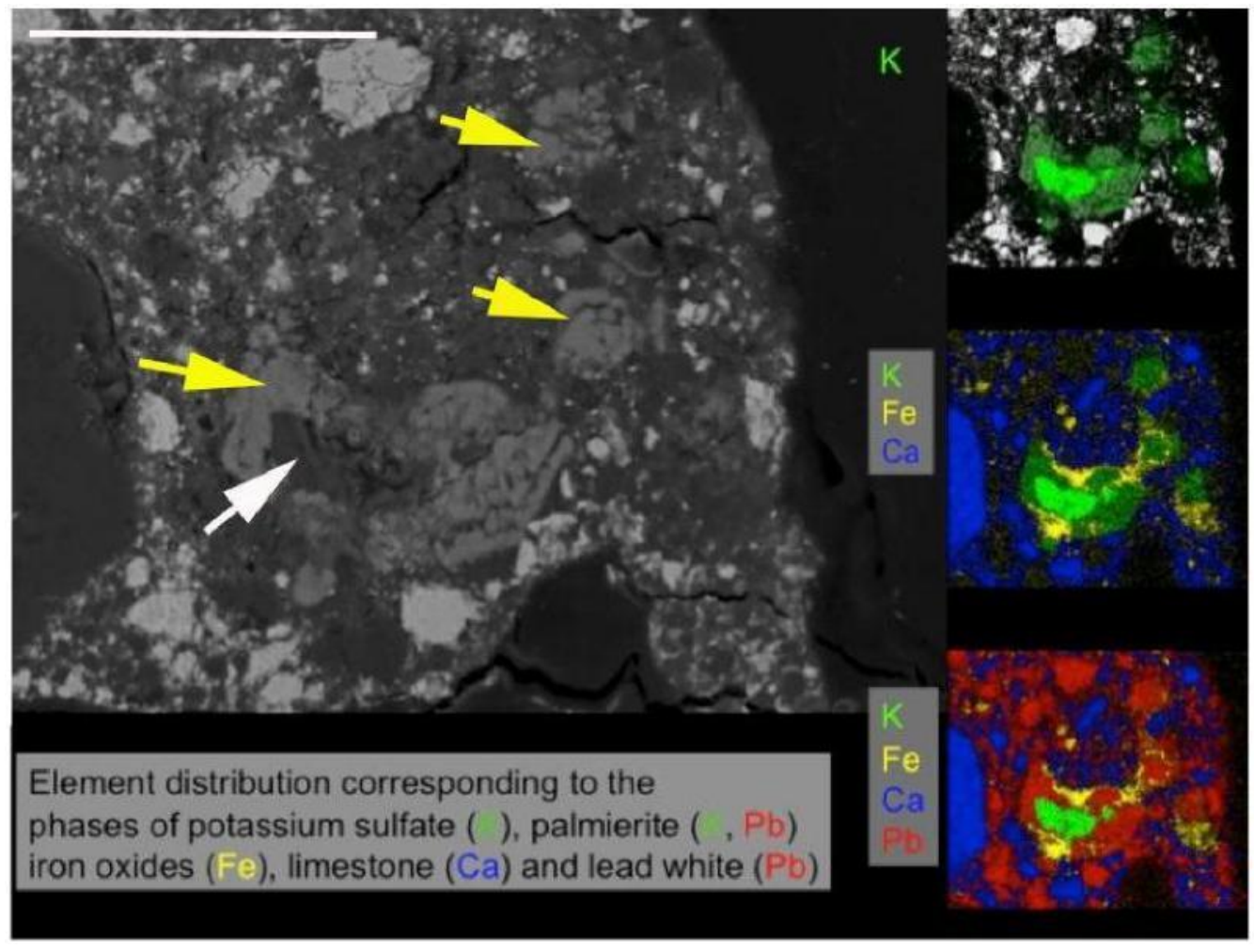

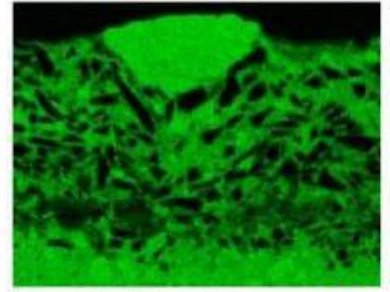

2A. LEAD MAP

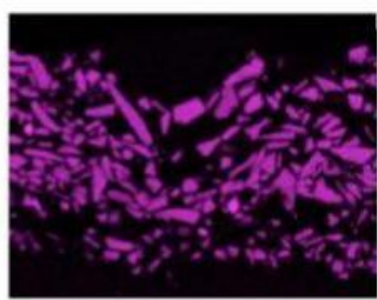

2B. SILICON MAP

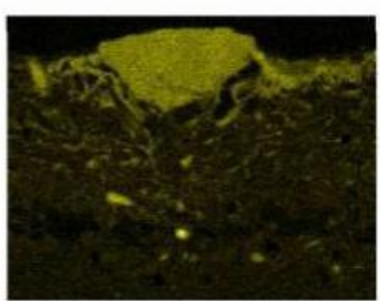

2C. POTASSIUM MAP

Fig 1. FE-SEM-BSE picture (20kV): Potassium sulfate aggregate (white arrow; high K as green) surrounded by palmierite (yellow arrow; spotted green/red) and iron oxides (Fe-K yellow) growing in the chalk (Ca-K blue) and lead white ( $\mathrm{Pb}-\mathrm{M}$ red) ground of a paint cross section from Art of Painting by J. Vermeer. Horizontal bar $50 \mu \mathrm{m}$.

Fig 2. EDX maps of a paint cross section with a $80 \mu \mathrm{m}$ x $35 \mu \mathrm{m}$ palmierite aggregate (potassium lead sulfate). Sample taken from the Jordaens's painting The Ferry Boat. Silicon represents the distribution of the degraded cobalt glass pigment. Potassium marks the palmierite aggregate. Lead marks the lead soap and lead white pigment distribution 